Sādhanā Vol. 29, Part 5, October 2004, pp. 509-523. @ Printed in India

\title{
Influence of processing and reinforcement on microstructure and impact behaviour of magnesium alloy AM100
}

\author{
S JAYALAKSHMI ${ }^{1}$, S SESHAN $^{1 *}, \mathrm{~S}$ V KAILAS ${ }^{1}, \mathrm{~K}_{\mathrm{KUMAR}}{ }^{1}$ and \\ S SRIVATSAN ${ }^{2}$ \\ ${ }^{1}$ Department of Mechanical Engineering, Indian Institute of Science, \\ Bangalore 560 012, India \\ ${ }^{2}$ Division of Materials Science and Engineering, Department of Mechanical \\ Engineering, The University of Akron, Akron, Ohio 44325-3903, USA \\ e-mail: seshan@mecheng.iisc.ernet.in
}

MS received 12 May 2004; revised 10 June 2004

\begin{abstract}
Reinforcing magnesium alloys with a discontinuously dispersed ceramic phase has engineered a new family of materials that are marketed under the trade name "metal-matrix composites". Continuous research efforts in the processing of these materials have provided the necessary impetus for their emergence and use in structural, automotive and even aerospace-related components. In this paper we report the results of a study aimed at understanding the role of short-fibre reinforcements (discontinuously dispersed through the metal-matrix of magnesium alloy AM100) on impact deformation and fracture behaviour. In particular, the role of volume fraction of the reinforcing phase on impact energy and fracture behaviour is presented and discussed. An increase in short-fibre reinforcement content in the magnesium alloy metal-matrix is observed to have a detrimental influence on impact energy when compared to the unreinforced counterpart. Micro cracking in the metal-matrix coupled with failure of the reinforcing fibres, both independently dispersed and in clusters, dominates the fracture sequence at the microscopic level. The final fracture behaviour of the composite material is discussed in the light of the concurrent and mutually interactive influences of nature of loading, local stress state, intrinsic microstructural effects and deformation characteristics of the composite constituents.
\end{abstract}

Keywords. Magnesium; metal-matrix composite; mechanical properties.

\section{Introduction}

In the last two decades most research and development efforts have aimed at reinforcing monolithic metals and alloys with a ceramic phase with the primary purpose of enhancing their properties, spanning the domains of physical, mechanical and fracture behaviour. Reinforced metal matrices are termed as metal-matrix composites (denoted henceforth as MMCs)

*For correspondence 
(Srivatsan et al 1981, 1995; Clyne \& Withers 1993; Lewandowski 2000). With rapid strides in the development, emergence and use of MMCs as potentially viable choices for a spectrum of performance-critical applications, even the not-so-high properties of pure metals and their alloy counterparts are significantly enhanced to make them attractive and economically affordable for structural applications. Initially, pure aluminum and aluminum-base alloys were chosen and used as the matrix for reinforcement with a ceramic phase (Srivatsan et al 1993). However, rapid advances in technological development provided the much-desired impetus for the growing interest and concomitant use of magnesium and magnesium-based alloys as the metal-matrix (Nair et al 1985; Taya \& Arsenault 1989).

Concurrent with rapid strides in the development, emergence and use of new and improved materials for a plethora of performance-critical applications, innovative techniques for processing these materials have also evolved. Casting processes were the initial techniques used for the production of MMCs. To keep pace with technological advances these processes have undergone dramatic improvements (Polmear 1980). The technique of squeeze casting offers several noteworthy advantages and has emerged as a potentially viable, cost effective, and economically feasible technique for the production of metal-matrix composites (MMCs) (Polmear 1980, 1994; Unsworth \& King 1986; Wei \& Dunlop 1992).

The last two decades have witnessed increasing demand and concurrent surge in lightweight structural materials for use in several performance-critical applications in the industries of aerospace, automotive and even commercially related products (Polmear 1980, 1994; Unsworth \& King 1986). Most significantly, the alloys of aluminum, titanium and magnesium have gained enhanced importance for use in such applications primarily because they have a combination of unique properties to offer (Polmear 1980, 1994). A few of the advantages are low density (light weight), good machinability, dimensional stability and low power consumption, which makes alloys of magnesium potentially viable and economically affordable choice is preferred to aluminum alloys and titanium alloys for performance-critical applications (Meschter \& Neil 1984; Das \& Davis 1988: Das 1989; Froes 1989). However, on the downside, the hazardous nature of magnesium in the molten state coupled with its susceptibility to oxidation cannot be overlooked (Das 1989; Froes 1989). With advancements in the fields of classical engineering and emerging technologies, many of the conventional problems encountered can now be overcome. However, mechanical properties and wear resistance of the magnesium-based alloys are inferior at elevated temperatures (Das 1989; Polmear 1994). A solution lies in developing reinforced materials from pure magnesium and magnesium-based alloys, which can offer improvements in properties, such as stiffness, hardness, strength, fracture behaviour, including wear resistance, similar to those observed in reinforced matrices of aluminum, copper and titanium. Reinforcing magnesium alloys either with ceramic particulates or ceramic fibres is likely to result in an improvement in certain mechanical properties, while also enhancing the thermal stability of materials with concomitant alteration of their responses to the chemical environment.

Several references are available in the published technical literature on squeeze casting of aluminum-based alloys (Das \& Chatterjee 1981; Franklin \& Das 1984; Chadwick 1991). However, only limited test data exists with respect to magnesium-based alloys. This shows that the technique of squeeze casting of pure magnesium and its alloy counterparts has not been thoroughly explored. Among the viable, efficient, and economically feasible methods used for the primary production of metal-matrix composites, the squeeze infiltration technique is most promising (Chadwick 1991). However, adequate information regarding processing of magnesium-based composites using the squeeze infiltration technique is not available. This justifies the need for an investigation with the primary purpose of generating meaningful 
data on magnesium alloys and their composite counterparts produced by the squeeze casting technique.

Rapid strides in emerging technologies have engendered considerable scientific and technological interest in magnesium-based composites. This is because they are economically affordable candidates for several structural applications and readily offer an attractive combination of properties, namely light weight, high specific stiffness $(E / Y)$, and specific strength $(\zeta / Y)$ (Emley 1966; Proffitt 1993). Such noteworthy combination of mechanical properties is due essentially to the presence of the hard, brittle and elastically deforming ceramic reinforcement phase in the soft ductile and plastically deforming metal-matrix. The increasing demand for magnesium alloys in newer generation automotive and aerospace components has necessitated the need for improvement in their properties particularly at elevated temperatures. This has been possible by engineering magnesium-based composites. A few of the current applications of magnesium alloy-based composites in the automotive industry are: (a) piston ring inserts, (b) gears, (c) gearbox bearings, and (d) connecting rods (Spare 1986). Advanced manufacturing processes, such as squeeze infiltration (which is an extension of the squeeze-casting technique) are becoming increasingly popular for the fabrication of magnesium-based composites for both laboratory-scale research and commercial purposes (Hu 1998). Most research studies conducted on magnesium-based composites and documented in the published literature are based on the $\mathrm{Mg}-\mathrm{Al}-\mathrm{Zn}$ alloy system (Jones $\mathrm{H}$ et al; Chang $\mathrm{C} \mathrm{F}$ et $a l$ ). The most popular among these are alloys reinforced with particulates of silicon carbide $\left(\mathrm{SiC}_{p}\right)$ and processed by the stir-casting technique (Mohan \& Gopalakrishna (1996). A recent technology update (Biswas et al 1999) provides a succinct overview of the properties of $\mathrm{SiC}$ reinforced (both whiskers and particulates) $\mathrm{Mg}-\mathrm{Al}-\mathrm{Zn}$ (AZ31, AZ61 and AZ91) alloys. These composites have shown notable improvements in mechanical properties such as elastic modulus (stiffness) and strength. A near similar enhancement in mechanical behaviour was also observed for saffil alumina-fibre reinforced magnesium alloy metal matrices Goldberg et al (1991). These composites have become more popular than metal matrices reinforced with zirconia and alumino silicate fibres Westengen et al (1990).

The objective of this research paper is to document the influence of processing and reinforcement on microstructure, impact response and fracture behaviour of magnesium alloy AM100-based MMCs. The kinetics governing impact fracture behaviour are discussed in the light of the concurrent and mutually interactive influences of the nature of loading, local stress state, the deformation characteristics of the composite constituents, and intrinsic microstructural effects.

\section{Materials and processing}

The material chosen for this study was magnesium alloy AM100 (Mg-10Al-0 $13 \mathrm{Mn})$ table 1 . The alloy was reinforced with saffil alumina $\left(\mathrm{Al}_{2} \mathrm{O}_{3}\right)$ short-fibres. Both the unreinforced and reinforced counterparts were produced by squeeze infiltration technique. Three different volume fractions $\left(V_{f}\right)$ of the reinforcement phase $(15,20$ and 25 vol. \%) were chosen. The saffil alumina fibre preforms (cylindrical cross-section of diameter $70 \mathrm{~mm}$ and height $35 \mathrm{~mm}$ ) were pre-heated prior to being inserted into the hot die. The standardization of melting and casting parameters (Recommended practices 1965), such as: (a) melt temperature, (b) melt holding time, (c) die temperature, (d) preform temperature, (e) pressure applied during squeezing, and (f) pressure holding time was initially optimized. The necessity for such standardization 
Table 1. Recommended chemical composition of alloy AM100.

\begin{tabular}{cccccccc}
\hline Element & $\mathrm{Al}$ & $\mathrm{Mn}$ & $\mathrm{Zn}$ & $\mathrm{Si}$ & $\mathrm{Cu}$ & $\mathrm{Ni}$ & $\mathrm{Mg}$ \\
\hline Weight $\%$ & $9.3-10.7$ & $0.13 \mathrm{~min}$ & $0.30 \max$ & $0.3 \max$ & $0.1 \mathrm{max}$ & $0.01 \mathrm{max}$ & Balance
\end{tabular}

comes in the wake of their influence in governing the overall quality of the final casting. The resultant composite is denoted as $\mathrm{AM} 100 / \mathrm{Al}_{2} \mathrm{O}_{3} / x x f$, where $x x$ denotes volume fraction of the reinforcing phase and $f$ refers to the nature of the reinforcing phase, i.e., fibres.

High purity magnesium, free from dust and contamination, was charged in a crucible of silicon carbide $(\mathrm{SiC}) \mathrm{kept}$ in an electric resistance furnace. The entire charge was covered with a thin sheet of aluminum foil prior to initiation of melting. The temperature of the furnace was maintained at $650^{\circ} \mathrm{C}$. Graphite powder was used as a cover for melting the alloy. Graphite aids in minimizing oxidation of magnesium by excluding oxygen and creating a protective atmosphere inside the furnace. Upon initiation of melting of pure magnesium, the temperature of the furnace was raised to $720^{\circ} \mathrm{C}$. The required quantity of aluminum was added and the resulting melt thoroughly stirred. With progressive melting the furnace temperature was raised to $780^{\circ} \mathrm{C}$ and the melt was held at this temperature for 10 minutes during which period the required amount of manganese was added. It was then skimmed to remove the oxides and impurities. The molten metal was continuously stirred in order to (a) ensure a near-uniform distribution of alloying elements, and (b) prevent the elements from settling at the bottom on account of their higher density.

Prior to pouring, a mixture of boric acid and sulphur was sprinkled on the melt surface. This aids in preventing spontaneous oxidation of the surface of the molten metal. The melt was then poured into the pre-heated die (coated with colloidal graphite) and mounted on the table of the squeeze-casting machine. The punch was lowered into the die and pressure was applied. The pressure applied was $40 \mathrm{MPa}$ for a duration of 30 seconds. For the $\mathrm{AM} 100 / \mathrm{Al}_{2} \mathrm{O}_{3} / x x f$ composite the pressure and time duration of its application were held constant at $40 \mathrm{MPa}$ for 30 seconds. The chosen pressure and time were optimized from a combination of data published in the open literature and initial experimental trials. The solidified casting was then ejected from the die.

Composites for all the three volume fractions of the alumina fibre reinforcement $\left(V_{f}=\right.$ $15 \%, 20 \%$ and $25 \%$ ) were produced under identical conditions of pressure and holding time. The only additional feature in producing the composites is that the preform was located in the die prior to pouring the molten metal. The preform was heated to a temperature higher than the melt $\left(850^{\circ} \mathrm{C}\right)$ so as to prevent premature solidification. A schematic of the preform used is shown in figure 1 . Prior to pouring the molten metal, the preform was placed inside a preheated die cavity. This was followed by: (a) pouring of the melt, (b) application of squeeze pressure for infiltration, and (c) solidification. The solidified casting of the AM100/ $\mathrm{Al}_{2} \mathrm{O}_{3} / x x f$ composite was eventually ejected. The die and punch were made from hardened steel (EN24) and the die was preheated using a portable heater. The specifications for the squeeze casting equipment are:

Press capacity: 50 tons

Approach speed: $100 \mathrm{~mm} / \mathrm{s}$

Return force: 25 tons

Pressing speed: 1 to $10 \mathrm{~mm} / \mathrm{s}$ 
(a)

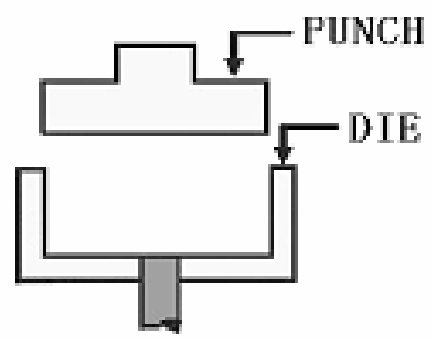

(c)

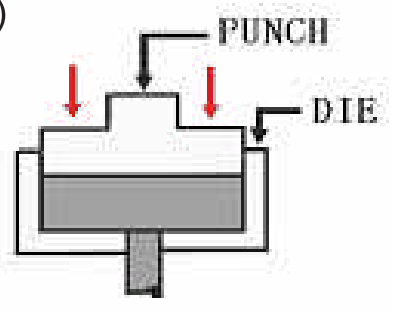

(b)

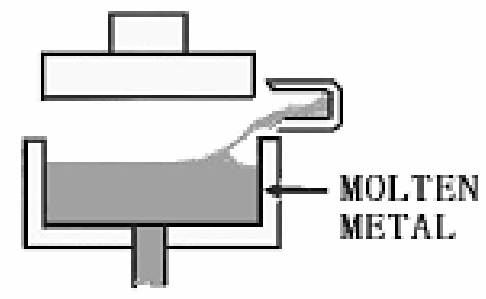

(d)



Figure 1. Schematic showing the sequence of steps during squeeze casting operation (a) Pre-heated die and punch. (b) Molten metal poured into the die cavity. (c) Application of squeeze pressure. (d) Ejection of solidified casting.

The process sequence and process parameters used for the production of alloy AM100 and the composites are shown in figure 2.

Both the unreinforced alloy and the reinforced composite counterparts were heat-treated. The heat treatment sequence essentially involved an interrupted solution heat treatment of the product at $410^{\circ} \mathrm{C}$ for $18-24$ hours. This was broken up into several intervals with intervening cooling periods: (a) $410^{\circ} \mathrm{C}$ for $6 \mathrm{~h}$, (b) $350^{\circ} \mathrm{C}$ for $2-3 \mathrm{~h}$, and (c) $410^{\circ} \mathrm{C}$ for $12-14 \mathrm{~h}$ (ASTM B 661 1993; AFS 1965). This was followed by quenching. The quenched samples were then artificially aged at $225^{\circ} \mathrm{C}$ to facilitate improvement in properties.

\section{Experimental characterization}

\subsection{Microstructure study}

Metallographic samples were cut from the unreinforced and reinforced samples of alloy AM100 after heat treatment. The cut samples were then mounted in Bakelite, and mechanically ground on progressively finer grades of $\mathrm{SiC}$ impregnated emery papers using water as the lubricant. The mounted and ground samples were then mechanically polished using onemicron size alumina powder suspended in distilled water. Final polish to near-mirror finish was achieved using 0.5-micron alumina powder suspended in distilled water. Reinforcement morphology and its distribution in the magnesium alloy metal-matrix and other key observable microstructural features were examined using: (a) an optical microscope (Model: Leitz Metallovert D) and photographed using bright-field illumination technique, and (b) a scanning electron microscope (JEOL JSM-840A) to facilitate high magnification observations of the size, intricacies in morphology and nature of distribution of the reinforcing phase (fibres) in the metal-matrix. 


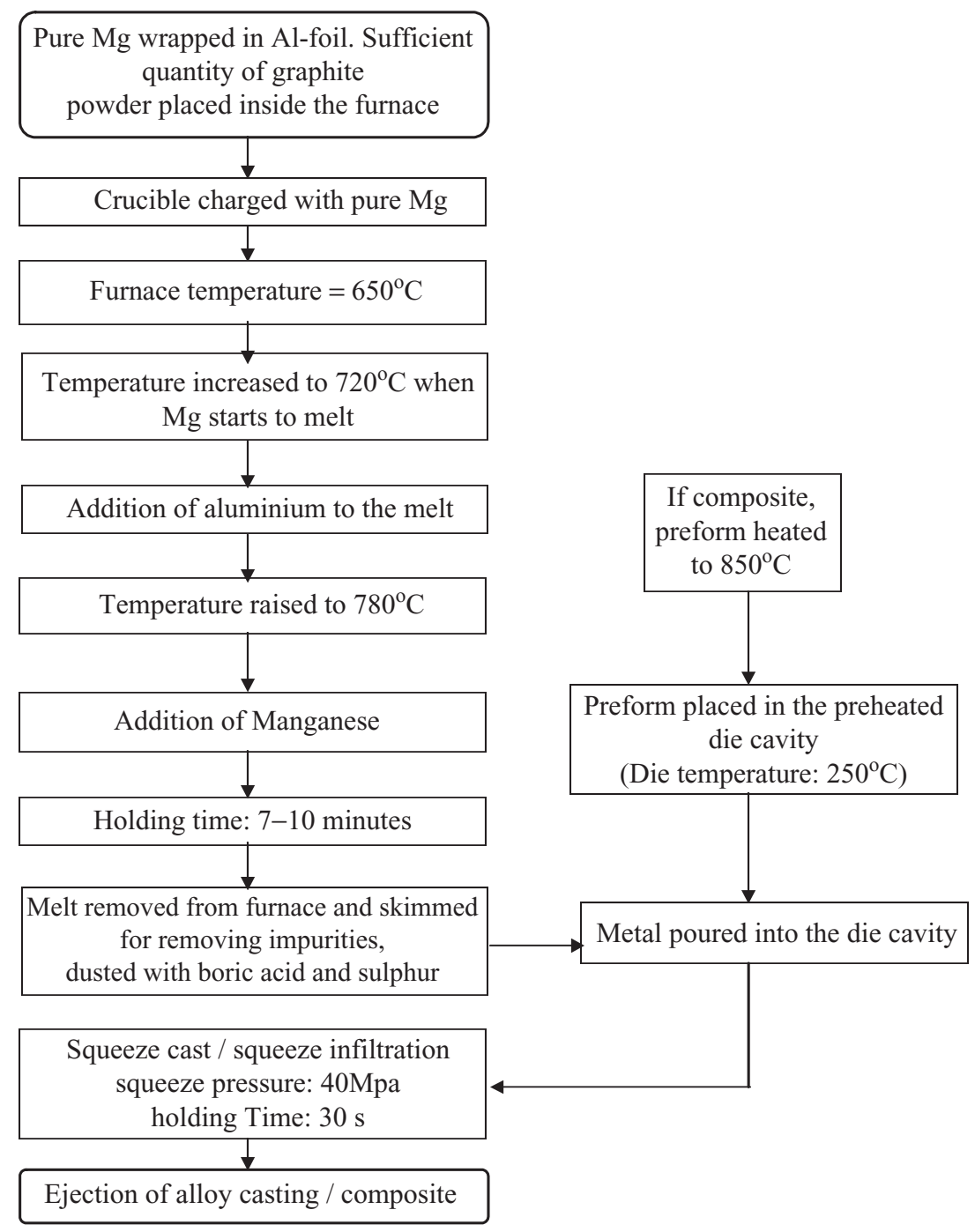

Figure 2. Flow chart depicting the process sequence and key process parameters governing the production of alloy AM100 and its composite counterparts.

\subsection{Densities and Young's modulus}

Densities of unreinforced alloy (AM100) and composite counterparts (AM100/ $\mathrm{Al}_{2} \mathrm{O}_{3} / x x f$ ) were determined based on weight-loss measurement using the specific gravity bottle method. Young's modulus values were independently assessed using the 'elastosonic' equipment, which is based on the principle of ultrasonic non-destructive testing (NDT).

\subsection{Hardness}

Hardness of the unreinforced alloy (AM100) and composites (AM100/ $\left.\mathrm{Al}_{2} \mathrm{O}_{3} / x x f\right)$, subsequent to heat treatment, was determined using the Brinell hardness test machine. The indenter 
used was a $10-\mathrm{mm}$ steel ball and the applied load was $500 \mathrm{kgf}$. An optimum aging sequence was established for both unreinforced alloy and reinforced counterparts. It was observed that the $\mathrm{AM} 100 / \mathrm{Al}_{2} \mathrm{O}_{3} / x x f$ composites took less time to reach peak hardness when compared to the unreinforced counterpart (AM100).

\subsection{Impact tests}

Impact tests were conducted using a fully instrumented Tinus-Olsen test machine (model number: 84). The machine can provide a range of impact energies from $0.2 \mathrm{~J}$ to $360 \mathrm{~J}$. The mass of the hammer chosen was $22.7 \mathrm{~kg}$ and the striking velocity range was $0.1 \mathrm{~m} / \mathrm{s}$ to $5.1 \mathrm{~m} / \mathrm{s}$. Three experiments were conducted on both unreinforced alloy and composites at (a) a constant striking velocity of $3.5 \mathrm{~m} / \mathrm{sec}$, and (b) a striking impact energy of $1.5 \mathrm{~J}$. The software (INSTRON: Dynatup) provided plots of (a) variation of load with time, and (b) variation of absorbed energy with time. Charpy impact tests were conducted on both unnotched and notched specimens of unreinforced and reinforced magnesium alloy. Test specimens measured $50 \times 10 \times 10 \mathrm{~mm}$. The notch had a depth of $2 \mathrm{~mm}$ and a notch tip radius of $0.02 \mathrm{~mm}$.

\subsection{Failure damage analysis}

Fracture surfaces of the deformed and failed impact samples were examined in a scanning electron microscope (SEM) [Model JEOL-JSM-84A] to (a) determine the macroscopic fracture mode, and (b) characterize the fine-scale topography and establish the microscopic mechanisms governing fracture. The distinction between the macroscopic mode and microscopic fracture mechanisms is based on the magnification level at which the observations are made.

\section{Results and discussion}

\subsection{Microstructure}

Microstructures of alloy AM100, in the as-cast condition, produced by gravity die-casting and squeeze casting are shown in figure 3 . When compared to its gravity die-cast counterpart, microstructure of the squeeze-cast AM100 alloy reveals an overall refinement in grain size coupled with absence of porosity. These features are attributed to the high applied pressure
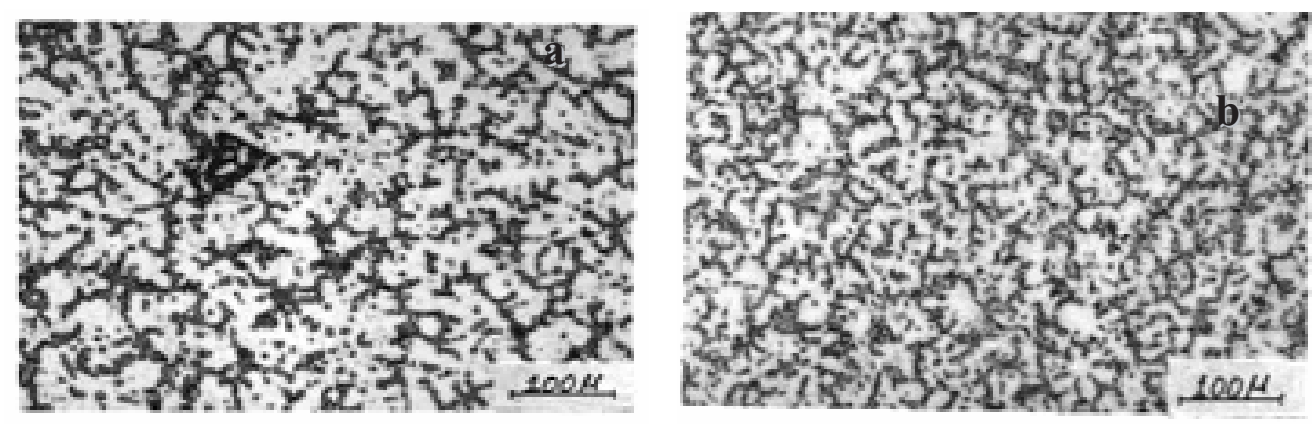

Figure 3. Optical micrographs of alloy AM100 in the as-cast condition showing microstructure of die cast sample (a), and squeeze cast sample (b). 


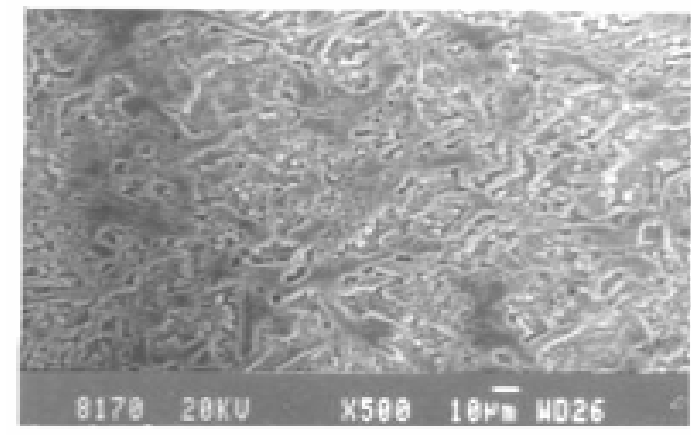

Figure 4. Scanning electron micrographs of the alumina short-fibre reinforced (volume fraction $=20 \%$ ) magnesium alloy composite produced by the squeezeinfiltration technique.

used in the squeeze-casting process. Under the influence of an applied pressure, there is no airgap formation between the solidifying metal and die-wall interface. This aids in dramatically enhancing the local heat transfer rate across the die surface, resulting in rapid solidification of the liquid metal. The applied pressure also aids in increasing the solubility of gases in the melt thus trapping the gases in solution. This helps in preventing the nucleation of bubbles in the melt with concomitant elimination of micro-porosity.

A representative microstructure of the squeeze-infiltrated AM10 alloy reinforced with 20 vol.\% of alumina fibres is shown in figure 4 . A near-uniform distribution of the alumina shortfibres through the magnesium alloy metal-matrix with no distinct evidence of clustering, or agglomeration is observed. This proves the effectiveness of the squeeze-infiltration technique for producing composite microstructures. No visible compression of the preforms occurs during the application of pressure. Presence of compression leads to the occurrence of fibre clustering and eventual damage through breakage, thereby lowering the mechanical properties of the composite.

In the as-cast condition, aluminum is present both in solid solution with the matrix and precipitated as the $\mathrm{Mg}_{17} \mathrm{Al}_{12}$ phase that is present both at and along the grain boundaries. Earlier studies on Mg-Al-Mn alloys Lunder et al (1989); Jayalakshmi 2002 revealed that the eutectic network consists of (a) primary alpha (Mg-matrix), and (b) beta phase $\left(\mathrm{Mg}_{17} \mathrm{Al}_{12}\right)$ present along the grain boundaries. Aging the as-cast material enhances precipitation of the beta phase $\left(\mathrm{Mg}_{17} \mathrm{Al}_{12}\right)$ along grain boundaries. The precipitation sequence for alloy AM100 is summarized in table 2. Figure 5 is a scanning electron micrograph of alloy AM100 showing fine precipitates dispersed along the grain boundary.

\subsection{Aging response}

Aging responses of the squeeze cast and die-cast samples are compared in figure 6. Squeezecast specimens exhibit observable increase in hardness and concurrent decrease in aging time

Table 2. Precipitation sequence for alloy AM100 (Polmear 1980).

\begin{tabular}{lc}
\hline Alloy system & Precipitation sequence \\
\hline $\mathrm{Mg}-\mathrm{Al}$ & $\begin{array}{c}\mathrm{Super}_{\mathrm{a}} \mathrm{Mg}_{17} \mathrm{Al}_{12} \text { (equilibrium precipitate) } \\
\end{array}$ \\
\hline
\end{tabular}




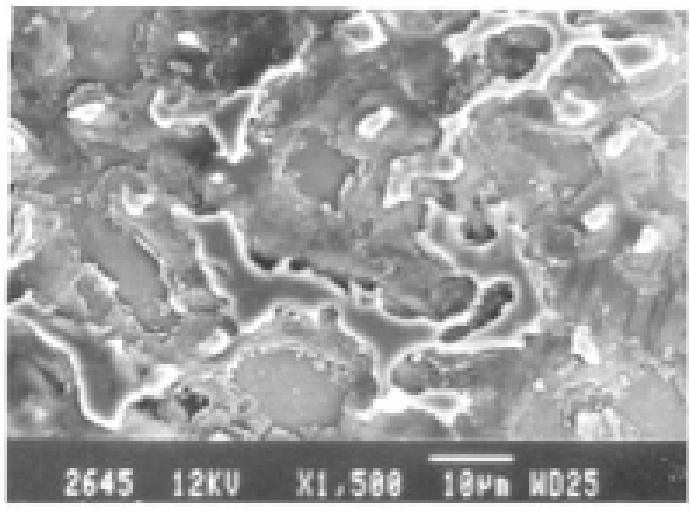

Figure 5. Scanning electron micrograph of alloy AM100 showing the region of matrix, eutectic and presence of $\mathrm{Mg}_{17} \mathrm{Al}_{12}$ precipitates along the grain boundary.

to reach peak hardness. This is attributed to the conjoint and mutually interactive influences of (a) grain refinement by squeeze casting, and (b) the formation and presence of the $\mathrm{Mg}_{17} \mathrm{Al}_{12}$ precipitates both at and along the grain boundaries. Fine grain size and distribution of these precipitates both within the grain and at grain boundaries contributes to acceleration of the aging response. This is responsible for the observed improvement in hardness of the squeezecast specimen for short time periods. The aging response (variation of hardness with time) of the AM100 composites for all three-volume fractions of the fibre-reinforcing phase in the metal-matrix is shown in figure 7. In comparison with the unreinforced magnesium alloy (AM100), a substantial improvement in hardness has been achieved in the reinforced metal matrices. The increase in hardness of the composite microstructure is at least twice that of the unreinforced counterpart.

It is interesting to note that in the reinforced magnesium alloy metal-matrix, as the volume fraction of alumina short-fibres in the magnesium alloy metal-matrix increases there is a monotonic reduction in the time required to reach peak hardness. The addition of shortfibre reinforcement to the magnesium alloy metal-matrix (AM100) increases the dislocation density at the fibre-matrix interfaces (Neih \& Karlak 1984; Lunder et al 1989). This is because of the differences in coefficient of thermal expansion (CTE) between the hard and brittle reinforcing fibre and the soft and ductile metal-matrix. The presence of high dislocation density at interfaces facilitates precipitation at these locations. The formation and

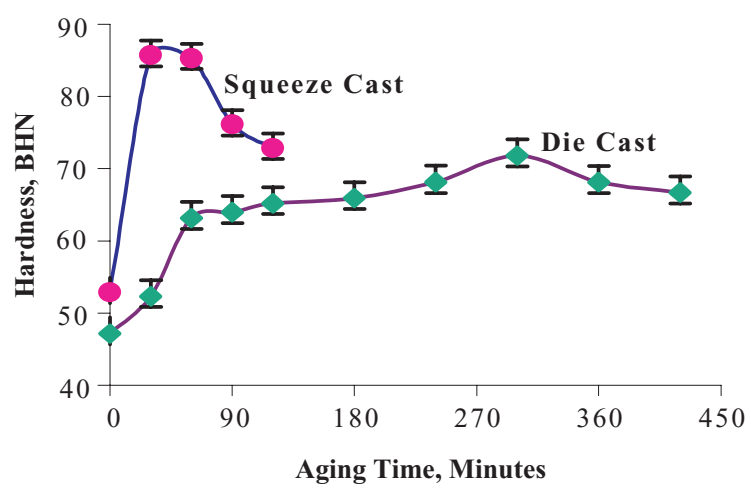

Figure 6. Influence of processing technique on variation of hardness (BHN) with aging time (minutes) for the unreinforced magnesium alloy AM100. 


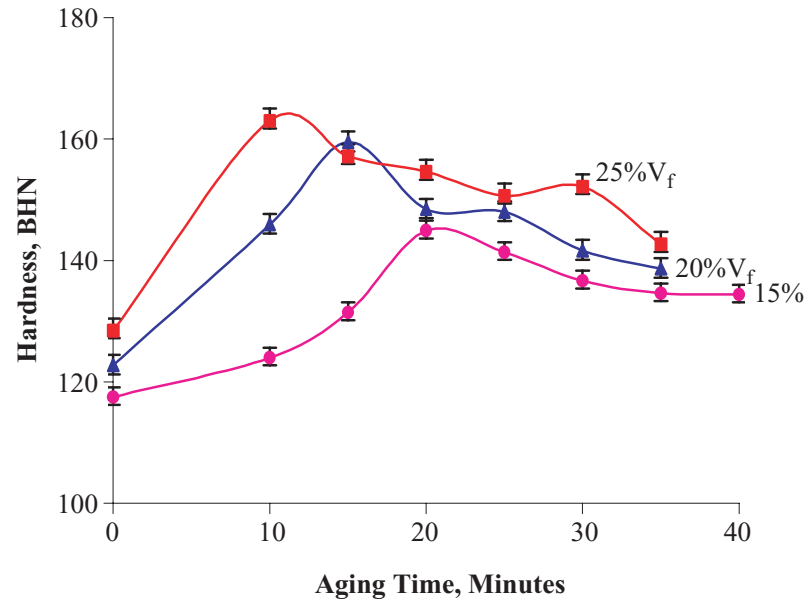

Figure 7. Influence of fibre volume fraction on variation of hardness (BHN) with aging time (minutes) for alloy AM 100.

presence of precipitates at the fibre-matrix interfaces may be appreciated by comparing micrographs of a single fibre in the as-cast state (figure 8a) and in the peak hardened state (figure $8 \mathrm{~b}$ ). The micrograph in the peak-hardened state (figure $8 \mathrm{~b}$ ) reveals precipitates covering the surface of the fibre (a) and also at the fibre-matrix interfaces (b). Similar behaviour of increased precipitation at interfaces was reported by Arsenault and co-workers (Neih \& Karlak 1984) for aluminum alloy 6061 reinforced with whiskers of silicon carbide. They attributed this to increase in dislocation density at interfaces. Increase in dislocation density strain hardens the metal-matrix locally and provides heterogeneous nucleation sites for precipitation, thereby accelerating the aging response (Neih \& Karlak 1984; Arsenault \& Shi 1986). Thus, an increase in volume fraction of the reinforcing fibres accelerates the aging kinetics, bringing about observable increase in hardness and concurrent decrease in aging time.
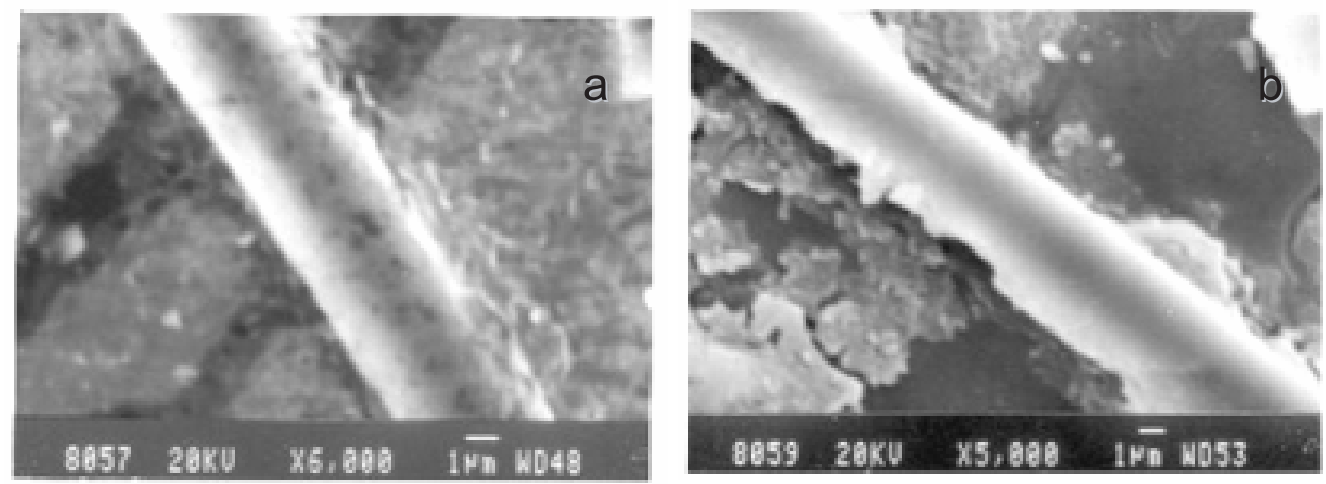

Figure 8. Scanning electron micrograph of (a) a single fibre in the as-cast condition, and (b) showing a single fibre in the peak hardened condition, revealing the presence of fine precipitates at the fibre-matrix interfaces. 
Table 3. Density and elastic modulus of alloy AM100 and composites.

\begin{tabular}{lcc}
\hline Fibre volume fraction $\left(V_{f} \%\right)$ & Density $\left(\mathrm{gm} / \mathrm{cm}^{3}\right)$ & Modulus of elasticity (GPa) \\
\hline Base alloy & 1.79 & 46 \\
$15 \%$ & $2 \cdot 07$ & 69 \\
$20 \%$ & $2 \cdot 17$ & 76 \\
$25 \%$ & $2 \cdot 29$ & 85 \\
\hline
\end{tabular}

\subsection{Density and modulus of elasticity}

The measured value of density of the base alloy (AM100) and the composite counterparts $\left[\mathrm{AM} 100 / \mathrm{Al}_{2} \mathrm{O}_{3} / x x f\right]$ are summarized in table 3 . Density of the reinforced magnesium alloy metal matrices is greater than the density of the unreinforced alloy (AM100), and increases with increase in volume fraction of the fibre-reinforcing phase (short-fibres) in the metalmatrix. The density of alumina fibres $\left(3 \cdot 3 \mathrm{~g} / \mathrm{cm}^{3}\right)$ is higher than the density of unreinforced magnesium alloy $\left(1.79 \mathrm{~g} / \mathrm{cm}^{3}\right)$. From the values of elastic modulus, determined by the elastosonic non-destructive testing method (Busk 1987; Kim et al 1989), and summarized in table 3 , it is seen that the modulus of elasticity increases with fibre-reinforcement content in the magnesium alloy metal-matrix. The inherently high stiffness of the reinforcing ceramic fibres is responsible for higher modulus of elasticity, which increases with fibre content in the metal-matrix.

\subsection{Impact response}

Impact tests were conducted on a fully instrumented Tinus-Olsen Charpy impact test machine using a striking velocity of $3.5 \mathrm{~m} / \mathrm{s}$. The impact energies of alloy AM100 and its composite counterparts, for both notched and unnotched conditions, are compared in figure 9. For both unreinforced alloy and composites the total energy consumed at fracture is more in the unnotched condition when compared to the notched counterpart. In notched test specimens, local stress concentration at the notch tip is conducive to failure during impact (Dieter 1988). This decreases the total energy required for failure of the test specimen. Further, it

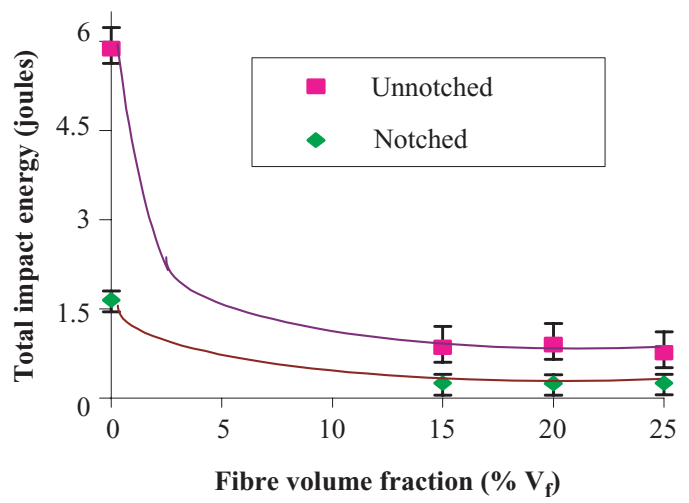

Figure 9. Variation of impact energy with fibre volume fraction for alloy AM 100: comparing the unnotched specimen with notched specimen. 




Figure 10. Variation of deflection at maximum load $(\mathrm{mm})$ with fibre volume fraction in alloy AM100 for both the unnotched and notched samples.

is also observed that for the unreinforced base alloy, for fracture to occur, the unnotched specimen absorbs four times the energy absorbed by the notched counterpart. Such a vast difference in the energy absorption capability prior to fracture is not observed for the composite. However, the total impact energy reduces on addition of reinforcing fibres to the metal-matrix and is independent of fibre volume fraction. Lim and co-workers (Kim et al 1989) and Kainer and co-workers (Purazrang et al 1991) showed that the brittle nature of the reinforcing alumina fibre plays a significant role in degrading the impact energy of the composite.

The variation of deflection (at maximum load) with short-fibre volume fraction is shown in figure 10. Unreinforced alloys reveal much higher deflection at the maximum load than reinforced composite counterparts. The inherently brittle nature and high stiffness of the reinforcing fibres are responsible for the low deflections experienced by the composites prior to catastrophic failure.

\subsection{Impact fracture}

Scanning electron microscope observations of the unreinforced alloy, in both the unnotched and notched conditions, are shown in figure 11. In unnotched test specimens the fracture surface reveals predominantly brittle intergranular failure (figure 11a). The intensity of intergranular failure increases for the notched test specimen with distinct evidence of cleavage-like features (figure 11b). The fracture surface of the $\mathrm{AM} 100 / \mathrm{Al}_{2} \mathrm{O}_{3} / x x f$ composite, for both the unnotched and notched conditions, is shown in figure 12. The composite material reveals evidence of micro cracking through the reinforcing fibres (figure 12a). As the volume fraction of the fibre reinforcement in the metal-matrix increases to $25 \mathrm{vol} \%$, failure occurs through a combination of partial breakage and total rupture (figure 12b). For notched test specimen, governing microscopic fracture mechanisms of the composite are intensified as seen in figure 13. In the composite, a large percentage of the reinforcing short alumina fibres have fractured. This is evident as protruding lips observed as the broken ends of the fibre. As volume fraction of the reinforcing fibres in the magnesium alloy metal-matrix increases, the fracture surfaces reveal intense slicing of fibres (both across and along the length) along the impact plane (figure 13b). 

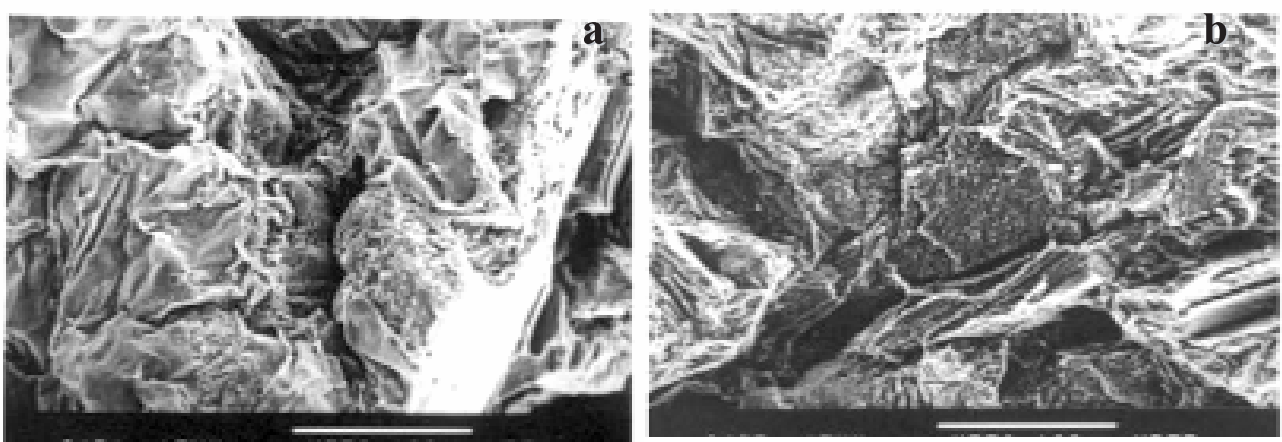

Figure 11. Scanning electron micrographs of the unreinforced alloy AM100 showing distinct evidence of intergranular failure in (a) unnotched and (b) notched samples.
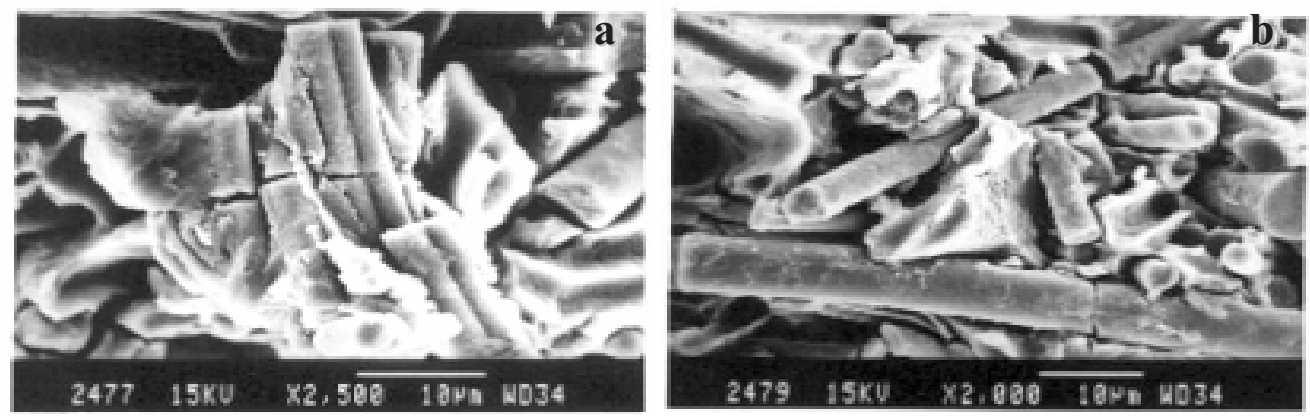

Figure 12. Scanning electron micrographs of the reinforced (25\%) alloy AM100 in the unnotched condition, showing (a) fine microscopic cracking through the fibres, and (b) fibre failure by rupture and decohesion at the interface.
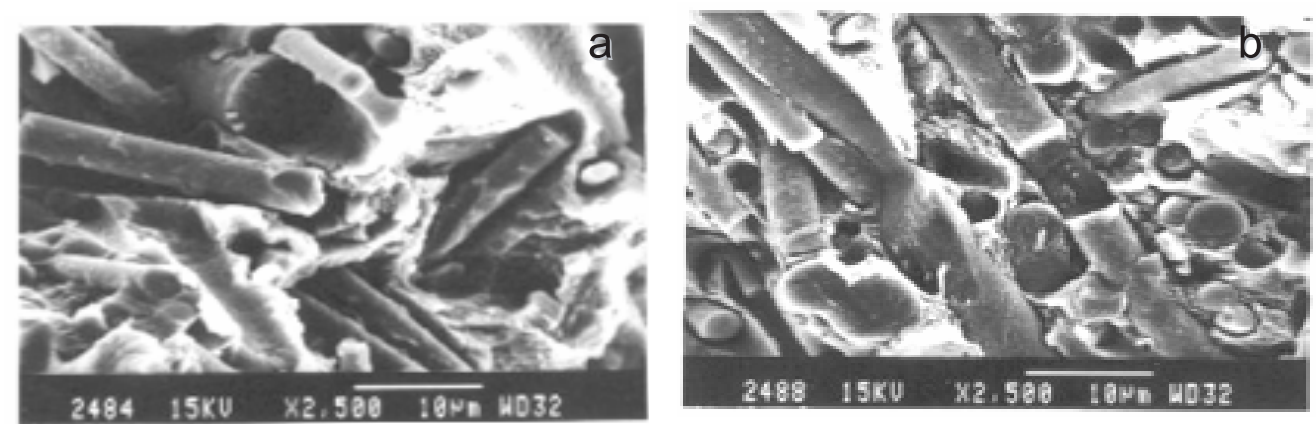

Figure 13. Scanning electron micrographs of notched samples of alloy AM100 reinforced with 25 vol. \% fibres, showing: (a) fibre rupture or breakage, and (b) slicing and decohesion of the fibres. 


\section{Conclusions}

(1) The technique of squeeze casting facilitates overall refinement in grain structure while concurrently eliminating porosity and ensuring that the resultant casting is sound and suitable for heat treatment. In reinforced magnesium alloy, the fibres are near-uniformly distributed through the matrix.

(2) The presence of hard, brittle and essentially elastically deforming precipitates $\left[\mathrm{Mg}_{17} \mathrm{Al}_{12}\right]$ both at and along grain boundaries makes the metal-matrix intrinsically hard. On reinforcing with short alumina fibres, the fibre-metal interfaces provide nucleation sites for precipitation, which enhances composite hardness while concurrently decreasing the aging time to peak strength.

(3) Density of reinforced metal-matrix is higher than that of the unreinforced counterpart (alloy AM100). Density increases with volume fraction of the reinforcing phase and is attributed to the higher density of the reinforcing short-fibres.

(4) Modulus of elasticity of the reinforced metal-matrix is twice that of the unreinforced counterpart (alloy AM100).

(5) While the presence of short-fibres in the soft metal-matrix enhances load carrying capability of the composite microstructure, concomitant decrease in time available for load transfer results in inferior impact resistance compared to the unreinforced counterpart. Further, the presence of hard and brittle fibres degrades the ability of the composite microstructure to deflect.

\section{References}

Arsenault R J, Shi N 1986 Dislocation generation due to differences between the coefficients of thermal expansion. Mater. Sci. Eng. 81: 175-187

ASTM B 6611993 Standard practice for heat treatment of magnesiun alloys (Philadelphia: American Society for Testing and Materials)

Biswas P K, Dev S C, Krishnan C S S 1999 Mg and composites as the future changing materials for automobile applications. Indian Foundry J. 45(3): 17-26

Busk R S 1987 Magnesium products design (New York: Marcel Dekker)

Chadwick G A 1991 Squeeze casting of metal matrix composites using short-fibre preforms. Mater. Sci. Eng. A135: 23-33

Chang C F, Das S K, Raybould D, Bye R L, Limoncelli E V Advances in powder metallurgy (New Jersey: Metal Powder Industries Federation) vol. 1-3

Clyne T W, Withers P J 1993 An introduction to metal-matrix composites (Cambridge: University Press)

Das S K, Davis L A 1988 High performance aerospace alloys via rapid solidification processing. Mater. Sci. Eng. 98: 1-12

Das S K 1989 Application of rapid solidification processing to high temperature alloy design. In high temperature alloy design (Warrendale: TMS-AIME) pp 451-471

Das A A, Chatterjee S 1981 Squeeze casting of aluminium alloys containing small amounts of SiC whiskers. The metallurgist and materials technologist $\mathrm{pp} 137$

Dieter G E 1988 Mechanical metallurgy (New York: McGraw Hill)

Emley E F 1966 Principles of magnesium technology (London: Pergamon)

Franklin J R, Das A A 1984 Squeeze casting - A review of the status. Bri. Foundrymen 77: 150-160

Froes F H 1989 Rapid solidification of lightweight metal alloys. Mater. Sci. Eng. A117, 19-29

Goldberg S, Westengen H W, Albright D L 1991 Properties of squeeze cast, magnesium-based composites. SAE Technical Paper Series No: 910830, SAE Detroit, Michigan 
Hu H 1998 Squeeze casting of magnesium alloys and their composites. J. Mater. Sci. 33:1579

Jayalakshmi S 2002 Processing and characterization of magnesium alloys (am 100 and zc63) and their alumina short-fibre reinforced composites. $\mathrm{PhD}$ thesis, Indian Institute of Science, Bangalore

Jones H, Joshi A, Rowe R G, Froes F J H 1987 The current status of rapid solidification of magnesiumbase and titanium-base alloys. Int. J. Powder Metall. 23: 13-20

Kim T, Lee S Y, Han K S 1989 Processing and failure mode of $\mathrm{Al}_{1} \mathrm{SiC}_{\mathrm{w}}$ MMC. Proc. Am. Soc. Composites, Ohio, pp 84-89

Lunder O, Lein J E, Aune T Kr, Nisancioglu K 1989 Role of $\mathrm{Mg}_{17} \mathrm{Al}_{12}$ phase in the corrosion of $\mathrm{Mg}$ alloy AZ91. Corrosion 45(9): 741-748

Lewandowski J J 2000 Fracture and fatigue of particulate composites: comprehensive composite materials. Metal matrix composites (ed.) T W Clyne (Elsevier) 3: 151-187

Meschter P J, Neil J E O 1984 Rapid solidification processing of magnesium-lithium alloys. Metall. Trans. A15: 237-240

Mohan V V, Gopalakrishna V G 1996 Technology for magnesium metal matrix composite. Indian Foundry J. 42(4): 5-9

Nair S V, Tien J K, Bates R C 1985 SiC-reinforced aluminium metal matrix composites. Int. Met. Rev. 30(6): 286-297

Neih T G, Karlak R F 1984 Aging characteristics of b//4c-reinforced 6061-aluminum. Scr. Metall. 25: $25-28$

Polmear I J 1980 Light alloys metallurgy of light metals, metallurgy and materials science series (London: Edward Arnold)

Polmear I J 1994 Magnesium alloys and applications. Mater. Sci. Technol. 10: 1-13

Proffitt H 1993 Magnesium and magnesium alloys. ASM Materials Handbook (Int. Materials Park, OH: Am. Soc. Mater.) 15: 798

Purazrang K, Kainer K U, Mordike B L 1991 Fracture toughness behavior of a magnesium alloy metal-matrix composite produced by the infiltration technique. Composites 22(6): 456-462

Recommended practices for sand casting of aluminum and magnesium alloys 2nd edn 1965 (Illinois: Am. Foundryman's Soc.)

Spare N C 1986 Modern strategy for magnesium in automobiles: Design prospects and material aspects of magnesium technology, proceedings of a conference, London, United Kingdom, pp 101110

Srivatsan T S, Sudarshan T S, Lavernia E J 1995 Processing of discontinuously-reinforced metal matrix composites by rapid solidification. Prog. Mater. Sci. 39: 317-409

Srivatsan T S, Sudarshan T S 1988 Mathematical modeling of rapid solidification. Rapid solidification technology: An engineer's guide (Lancaster: Technomic Publishing Company)

Taya M, Arsenault R J (eds) 1989 Metal-matrix composites: Thermo-mechanical behaviour (New York: Pergamon)

Unsworth W, King J F 1986 Proc. Int. Conf. on Magnesium Technology (London: Institute of Metals) pp 25-29

Wei L Y, Dunlop G L 1992 Magnesium alloys and applications (Oberursel: Germany)

Westengen H, Albright D L Aularg Nygard 1990 Development of cast magnesium matrix composites. SAE Technical Paper Number No: 900534, pp. 606-616 